\title{
Knowledge Sharing in Young Startups-First Quantitative Steps
}

\author{
Jouni A. Laitinen (ㅁ, Dai Senoo \\ Department of Industrial Engineering and Economics, Tokyo Institute of Technology, Tokyo, Japan \\ Email: Laitinen.j.aa@m.titech.ac.jp, Senoo.d.aa@m.titech.ac.jp
}

How to cite this paper: Laitinen, J.A. and Senoo, D. (2019) Knowledge Sharing in Young Startups-First Quantitative Steps. Journal of Service Science and Management, 12, 495-520.

https://doi.org/10.4236/jssm.2019.124034

Received: May 1, 2019

Accepted: June 15, 2019

Published: June 18, 2019

Copyright $\odot 2019$ by author(s) and Scientific Research Publishing Inc. This work is licensed under the Creative Commons Attribution International License (CC BY 4.0).

http://creativecommons.org/licenses/by/4.0/

\section{(c) (i) Open Access}

\begin{abstract}
This study aims to shed light on what influences knowledge sharing motivation in startups, which was chosen as the research topic due to its implications for theory development in knowledge sharing and startup fields. Hypotheses related to vision for the company, organizational culture, knowledge sharing motivation and knowledge sharing intention were developed based on a literature review and later tested using Structural Equation Modelling with a novel data set which was gathered from young startups. Vision for the company was found to be linked to all used types of knowledge sharing motivation types while organizational culture was linked to one of the three types. Enjoyment in helping others and reciprocal benefits were found to influence knowledge sharing intention while extrinsic motivators were found to be not influential for knowledge sharing intention.
\end{abstract}

\section{Keywords}

Knowledge Sharing Motivation, Organizational Vision, Organizational Culture, Startups, Incentives

\section{Introduction}

Startups operate in a turbulent environment [1] while searching for a suitable business model [2]. Due to the uncertainty in the operating environment, startups need to make most of their limited resources that they have managed to gather [3]. Previous research has shown that the vision for the company and organizational culture inside the startup are major reasons why individuals join startups [4] [5] and as such managers should leverage these factors to increase the likelihood for the company's survival. Knowledge sharing can be one of the ways to achieve this.

Knowledge sharing has been shown to be a significant component in influen- 
cing how the vision for the company [6] and organizational culture [7] are spread through the organization. As a significant number of startups fail [8], better knowledge sharing practices can help improve company survival rates and business performance [9]. Hence, increasing the amount of knowledge shared between the startup's members is important for future success. However, previous research on startups has focused on mature startups [10] [11], which leaves open questions related to the influence of organizational culture and vision for the company on knowledge sharing motivation in young startups. Therefore, this article aims to answer the following research question: how does vision of for the startup and organizational culture influence knowledge sharing motivation and knowledge sharing intention inside startups? By having a more in-depth understanding of the relationships between vision for the company, organizational culture and knowledge sharing intention, managers can better design programs that support active sharing of knowledge.

One challenge currently faced by practitioners is the applicability of previous research on small companies to startups since previous research has shown that startups differ from small companies in their goals, risk appetite and the geographic distribution of members among other factors [3]. These factors influence the internal organization of the startup thus causing uncertainty in the applicability of previously derived results. The inclusion of contextual factors into research has been proposed as one way to solve the existing inconsistencies such as this in the body of knowledge sharing research [12]. Given that existing research on knowledge sharing in startups is limited [13], there is a need for more research in order to better understand how the startup context influences knowledge sharing.

The rest of the article is structured as follows: first, differences between startups and small companies are discussed. After this, literature related to knowledge sharing, motivation, vision for the company and organizational culture are reviewed. Then, hypotheses targeting knowledge sharing in startups, the used instruments and the sample are presented. Next, the results of the analysis are presented and discussed. Finally, the article concludes with practical implications, limitations of the research and future research directions.

\section{Literature Review and Hypothesis Development}

In order to better understand how organizational culture and vision for the company influence knowledge-sharing motivation, a survey of existing literature was carried out. The literature review focused on organizational culture, vision for the company, motivation, and knowledge sharing intention with special focus on the startup context. As the literature review will show, understanding the interrelationship between these factors is critical in order for any knowledge sharing program to achieve the wanted outcomes. However, before discussing the factors influencing knowledge sharing motivation, the characteristics that differentiate startups from traditional small companies are discussed. Through 
this effort to contrast the two organizational types, an understanding of the differences in the organizational context and how knowledge sharing practices might differ can be understood.

After showing that a gap exists in the current body of knowledge sharing research through a thorough literature review, hypotheses are created to target this research gap.

\subsection{Literature Review}

\subsubsection{Comparing the Characteristics of Startups and Small Companies}

Differentiating startups from small companies has been a challenge in previous research. While most research refers to startups as companies in the early stage of their life cycle, it appears that a standard definition for a startup does not exist [15] and generic factors, such as company age, are often used as proxies. This lack of a standard definition for a startup can cause problems as the studied companies can be anywhere between one to three [16] or up to 12 years old [15], which is wide enough to contain many types of companies. If companies such as Twitter and Uber were startups when they were founded, then how did they differ from small companies?

The difference between small companies and startups is discussed by Aulet and Murray [3], who describe five key differences, between "SME entrepreneurship" and what they call "innovation-driven entrepreneurship, IDE" (i.e. startups). Calling the second type "innovation-driven" emphasises the core difference between the two types: IDEs have innovation in their core and leverage said innovation is critical for the survival of that company. Second, IDEs focus on serving the global markets from the start by leveraging diverse funding sources including venture capital whereas most small companies serve local markets backed by traditional funding sources. The third major difference is that members of the startup do not have to be located in the same location. Instead the members can be distributed globally.

Another critical difference is shown in the definition of a startup by Blank and Dorf [2] who define a startup as a "temporary organization in search of a scalable, repeatable, profitable business model" (p. xvii). They emphasise that the startup's business model is not set in stone from the start, but it will try to discover a sustainable business model. If the current assumptions about the business model are discovered to be false, the startup can "pivot" to target another market segment or to use another business model [17]. This flexibility of the business model is another key difference to SMEs.

Based on the above, a startup is defined as follows: a startup is a young innovation-driven organization searching for a repeatable and profitable business model through creating innovative products and services that target the uncertain global markets.

As the majority of startups fail [8], improving organizational and business performance is critical for the survival of the organization. Previous research has 
indicated that vision for the company and organizational culture are significant factors in motivating individuals to join and stay at startups [4] [5] and that their low formalization emphasises flexible knowledge sharing practices [18]. As knowledge sharing is linked to improved organizational and business performance [19], understanding the influence of organizational culture and vision for the company on knowledge sharing motivation is important.

\subsubsection{Knowledge Sharing Intention}

Knowledge sharing can be defined as using and sharing of insights and knowledge with other members of the organization [20]. Since individuals cannot be forced to share knowledge [21], it is important to make sure that the members of the organization contribute all relevant knowledge. As it is almost impossible to check if individuals are sharing everything they know, managers need to make sure that members of the organization are motivated to share.

Motivators for knowledge sharing intention have been discussed in two more extensive reviews of existing research [19] [22]. Wang and Noe [19] focused on a literature review while Witherspoon et al. [22] carried out a meta-analysis of existing research. Both reviews focused on individual-level factors influencing knowledge sharing and indicated that factors such as expected organizational rewards, shared goals, and subjective norms were positively linked with knowledge sharing intention. While mostly disregarded by the two reviews, the importance of organizational context was highlighted in previous research [12] [23] as an important factor that can help understanding the relationship between organizational context and knowledge sharing motivation.

As knowledge sharing takes place in an embedded context [24], by failing to describe the contextual factors of the research, understanding the reasons why knowledge sharing takes place becomes challenging. To help future research deal better with the contextual factors of knowledge sharing, Sergeeva and Andreeva [12] proposed a "who, where, why, what" description method as a way to describe the particular contextual factors of research. For example, using this framework to analyse previous conflicting results from incentive studies could result in a deeper understanding of how incentives and the contextual factors of knowledge sharing interact.

While a literature review carried out on KM research in the startup context [13] noted a general lack of research on KM in startups, the limited existing research includes research into the influence of knowledge sharing done by founders and its link to breaking even [9], and reciprocal benefits of knowledge sharing in proximally close startups [25]. In these studies, as in many others, there is a common assumption that people are naturally motivated to share knowledge with others, which cannot be assumed to be true without a more thorough analysis of the sharing motivations of the individuals. To be able to carry out this in-depth analysis, a deeper understanding the fundamental characteristics of motivation is needed in order to improve the chances of knowledge sharing activities to achieve their full impact potential. 


\subsubsection{Motivation}

Motivation is defined as to be moved to carry out an action [26]. Researchers usually divide motivation into two broad types: intrinsic and extrinsic motivation. Intrinsic motivation is defined as engaging in an activity without any apparent rewards whereas extrinsic motivation is defined as engaging in an activity that is incentivised by some form of reward [26]. While previous meta-analyses of experimental studies have shown both positive [27] and negative [28] influence of incentives on motivation, the two motivation types can work in unison to improve performance if the incentives to carry out a specific task have constructed appropriately [29].

Extrinsic motivation relies on incentives such as monetary compensation for the completion of a task. In an organizational context, relying purely on extrinsic motivation can be challenging as designing contracts and incentives that cover all aspects of work is complicated and such contracts would make it difficult for the employee to engage in any non-measured tasks [30]. Hence, in regards to extrinsic motivators, the managements' focus should be to make sure that the used incentives align with the task it has been assigned.

According to Lindenberg [31], intrinsic motivation has two subcategories: enjoyment-based and obligation-based intrinsic motivation. Enjoyment-based motivation is grounded on the idea that a person will engage in an activity if it improves her feelings. The more an activity enables the person to feel improvement in their condition the longer the person will engage in the activity without any external reward. The second type, obligation-based motivation, or "the goal to act appropriately" ([31], p.330), is founded on the idea that individuals want to behave in a manner that is suitable to the particular context which is reliant on individual acquisition of group norms.

Analysis of the underlying motivations can be challenging as "simply assuming that either money or enjoyment will dominate the activity without also looking at the role of the goals in the background leads to wrong conclusions about motivation" ([31], p.339). Hence, understanding the norms of suitable behaviour in the given organizational context and the types of incentives used are crucial for an accurate analysis of the motivations for individuals engaging in any specific activity. This is particularly relevant when looking at organizations which are still developing the foundations of the organizational culture, such as in young startups because the foundations of group norms are still developing.

\subsubsection{Vision for the Company and Organizational Culture}

Vision for the company can be defined as an "idealized goal to be achieved in the future" ([32], p.145). Vision has a vital role to play in organizational aspirations, and it is a source of motivation [33] [34]. In an entrepreneurial firm context, it has been shown that companies which didn't have a concrete vision or it had not been clearly communicated performed worse than those that did [35]. Additionally, it has been showed that the visions of for-profit and non-profit entrepreneurial companies differ and influence the strategies used by the companies [32]. 
These differences in operations and strategies have an impact on the organization's culture. Organizational culture is defined by Schein ([36], p.9) as "the basic assumptions and beliefs that are shared by organizational members." Organizational culture is linked to organizational performance [37], and it plays an important role in influencing knowledge sharing [7].

Organizational culture has a two-fold function in startups: it guides behaviour and also motivates. Startups frequently rely on informal control of work [10] where things just need to be taken care of [38] implying that the individuals' tasks are not strictly defined. In environments that de-emphasises rigid job division and hierarchy, such as in startups, workers are more motivated to take on hard problems [39]. As the organizational culture sets guidelines for expected behaviour, being able to act according to the expected norms is a motivator for the members [31]. Organizations, whose life depends on innovation, therefore, need to have an organizational culture, which emphasises knowledge sharing and taking on challenges.

The importance of founders and early core team as a source of culture has been previously discussed by Schein [36] and more recently by O'Reilly et al. [37] and Zaech and Baldegger [15], all of whom noted the long-lasting impact of founders have on the organizational culture. In larger, more established startups, Baron and Hannan [10] reported that changing the organizational culture later, even after the founders had exited the company, was both challenging and costly. These results place importance on spending time on early culture-building activities. This was also indicated by Nelson [40] who summarised the reasons for the success of a startup versus the failure of a university in a spinoff case as "... a matter of getting the right people in the right organizational context." (p.1152). In other words, the right people working towards realizing the right vision of the company.

In the startup context, vision plays two roles: it motivates employees and helps to coordinate tasks within the organization. Startups aim to create a growth-oriented business to target a specific goal [2] [17] with the founders creating its vision. During its early life, the startup is operating with limited resources and starts its life by making a loss [41] meaning that it cannot use a significant amount of resources to attract new employees. Vision has been noted as one way to attract new employees to the company [35], which was later confirmed by further research [5]. In mature startups, Baron and Hannan [10] found that identification with the company and its vision were important factors for employee retention, which found support in later studies [42]. O'Connor [43] reported that founders frame the narrative of the company differently depending on the listener. Of particular interest are "vision stories" shared by founders ([43] p.44), which are important when startups want to create a new market [11] or to attract more resources to the company.

The second reason why vision is essential for startups is due to vision's influence on coordination within the organization. In the SME context, organizational vision provides a framework for the daily actions taken by the organization 
members [44]. Hence, a well-communicated vision can help daily coordination within the startup and lead to better business performance [42]. The importance of knowledge sharing in the vision sharing process has been noted by Ensley and Pearce [4] and de Mol et al. [6]. Additionally, previous research [15] has noted the motivating impact of founders communicating the vision to startup members. By pursuing the vision through daily activities, the founders set the guidelines for the organization's culture.

The presented review point towards the importance of vision for the company and organizational culture as factors that guide daily behaviour and serve as sources of motivation for the members of the organization. As such, these factors are important for all organization to properly manage in order to increase their chances for success, particularly for companies that are still building their organizational practices. However, it is unknown how these factors influence knowledge sharing in the young startup context. Given that most startups fail [8], it is essential for practitioners to create a solid foundation for suitable knowledge sharing practices right from the start. While some guidance could be derived from research carried out in small companies, but to the differences in the organizational characteristics [3], understanding how to tailor practices can be challenging. As a result, understanding the influence of vision for the company and organizational culture on knowledge sharing motivation in the startup context can have a significant impact on management practices and on company survival.

\subsection{Hypotheses Development}

The presented literature review shows that there is a research gap on how vision for the company and organizational culture influence knowledge sharing motivation and intention in startups. Therefore, hypotheses targeting this gap were created.

\subsubsection{Extrinsic Motivation to Share Knowledge}

Extrinsic motivation is engaged when an activity is carried out to attain a separable outcome from the task [26]. Research on extrinsic motivators has found a positive effect of incentives on the motivation-performance link when incentives are appropriately configured [29]. Within knowledge sharing research, previous research on the use of expected organizational rewards to encourage knowledge sharing has derived both positive [22] and negative results [45].

In the startup context, financial benefits have been found to be one of the motivations to start a new company [46], why job-seekers want to join startups [5] and why individuals stay employed at that organization [10]. In experimental settings, extrinsic motivators have been shown to influence startup member performance [47]. Therefore, previous research indicates that expected organizational rewards should increase knowledge sharing intention.

H1: Expected organizational rewards are positively linked to knowledge sharing intention. 


\subsubsection{Intrinsic Motivation to Share Knowledge}

Lindenberg [31] argues that intrinsic motivation can be divided into two types: one related to improving one's feelings, and the other to the goal of acting appropriately. The more these feelings are engaged, the longer the individual engage in the task. The former is influenced by factors such "providing behavioural confirmation by self ("free choice" and "feeling of competence"), providing behavioural confirmation by others, $\ldots$ and allowing of improvement of nontangible resources (such as skills and competencies)" ([31], p.332). The latter is influenced by following the rules and norms of the group. ([31], p.335)

Previous research has shown that the organizational environment in startups is a critical factor in why individuals join and stay in the organization [5] [10]. As work coordination inside startups is often based on informal coordination [10], members are expected to help others in order to fulfill the vision of the company. When engaged in sharing knowledge, feedback received from helping others should be a significant motivator for the individual. The rationality behind this assumption is that by engaging in knowledge sharing with others, the individual's motivation would be boosted by the feeling of competence, the received information on the individual's performance level and by receiving positive feedback from others through contributing to the solving of a challenging problem ([31], p.332). Support for helping others as a motivating factor has been previously found in established companies [48]. These results imply that enjoyment in helping others should increase knowledge sharing intention.

$\mathrm{H} 2$ : Enjoyment in helping others is positively linked to knowledge sharing intention.

Another factor influencing motivation to share is the reciprocal benefits from the sharing [49]. Reciprocity is defined as responding likewise to the behaviour one receives [50], and it aligns with the second type of intrinsic motivation described by Lindenberg [31]. In a frequently-interacting environment, norms supporting reciprocity are expected to arise [51]. As such, reciprocity is expected from the other members of the startup as frequently-interacting members are working together towards a unified goal. Therefore, reciprocity has particularly potent implication for young startups where salaries often are compensated through giving out stock, which if the startup fails, will be worthless.

Reciprocal benefits have been studied in cases such as large companies from South Korea [52], and with credit union employees in Canada [53], with both researchers finding support for reciprocity increasing knowledge sharing levels. In the startup context, inter-startup reciprocity has been identified as having a significant influence on knowledge transfer and innovation performance [25]. Hence, it is hypothesised that:

H3: Reciprocal benefits from knowledge sharing is positively liked to knowledge sharing intention.

\subsubsection{Vision for the Company}

Effects of vision for the startup range from attracting new members [35] and 
motivating employees [15] to helping to coordinate actions within the organization [9], and it has been previously linked to organizational performance [4]. From a theoretical point of view, Zaecher and Baldegger [15] indicate that leaders motivate by "communicating an inspiring vision of the future" (p.158) to the other members of the organization. Young startups function on minimal resources [3] requiring founders and early team members to leverage their non-monetary resources to motivate members of the organization to work together [43] This ability to motivate employees to work together through the communication of vision is particularly important given that startups face a turbulent environment [1] where a significant number of startups fail [8]. Pursuing a motivating vision, which is one of the reasons why individuals choose to work in startups [10], can also help boost employees' willingness to take on more challenging tasks. As members engage in multiple tasks [38] through frequent interaction motivated by a single goal, reciprocal organizational norms are expected to arise [51]. At the same time, the equity the company offers can be a significant reason for joining a startup [5], which becomes worthless if the organization fails.

Based on these, it is hypothesised that vision for the startup influences both extrinsic and intrinsic motivation types to share knowledge. In detail, it is hypothesised that:

H4a: Vision for the company positively influences expected organizational rewards.

H4b: Vision for the company positively influences enjoyment in helping others.

$\mathrm{H} 4 \mathrm{c}$ : Vision for the company positively influences reciprocal benefits.

\subsubsection{Communal Sharing}

Startups consist of frequently interacting individuals working towards a unified goal [3] in a low formalization environment [18] where tasks just need to be taken care of without greater considerations to the division of roles [38]. Particularly, identification with the company goals, informal control of work allowing for autonomy and individual responsibility are important motivators for the members [10]. This type of organizational culture is one of the reasons why individuals join startups [5].

Based on these descriptions of a "startup culture," it is proposed that the organizational culture within a startup resembles what Fiske [14] calls Communal Sharing, CS, relationships. Fiske states that these types of relationships influence both motivation and norms (p.693). According to the theory, individuals in a CS relationship often think that they share something bigger making it natural to be altruistic towards one another ([14], p.691). The members can receive without giving anything but are expected to contribute and help those who ask for it with public goods being assumed to belong to everybody ([14], p.693). Given that knowledge can be theorised as a public good [20], it is therefore expected to be shared with those who want to gain access to it. According to Fiske's theory, members would seek to contribute knowledge to the group without expecting any payments in return ([14], p.697). It is expected that individuals contribute 
tasks according to their capabilities until the work is finished without any explicit division of work ([14], p.697).

Startup culture and CS cultures have many parallels: both describe frequently interacting individuals working towards something bigger that is held in common with others and contributing to tasks until they are done without explicit control or expectation of immediate rewards. The applications of CS in previous knowledge sharing research are limited to theoretical studies [54].

Based on the above, it is hypothesised that:

H5a: Communal Sharing is not significantly linked to expected rewards.

H5b: Communal Sharing is positively linked to enjoyment in helping others.

$\mathrm{H} 5 \mathrm{c}$ : Communal Sharing is positively linked to reciprocal benefits.

Finally, it is hypothesised that a covariance relationship exists between the vision for the company and communal sharing. This based on the findings that link organizational vision to organizational culture [32]. Particularly, the core members of the early team create the norms of interaction [32] [40] and organizational culture [36]. The core team sets the example of what is expected in the roles they have [38]. As vision and strategies used have been found to be linked [5], the relationship between vision and organizational culture poses a question over their relationship in the startup context. Hence, it is hypothesised:

H6: There will be a significant covariance link between the vision for the company and Communal Sharing.

\section{Research Methodology}

The overall research framework created based on the hypotheses presented above is shown in Figure 1.

\subsection{Measures}

Measures to study the presented hypotheses were adopted from previous studies on knowledge sharing motivation, entrepreneurship, and relational models. The measures for Expected Organizational Rewards (OR), Enjoyment in Helping

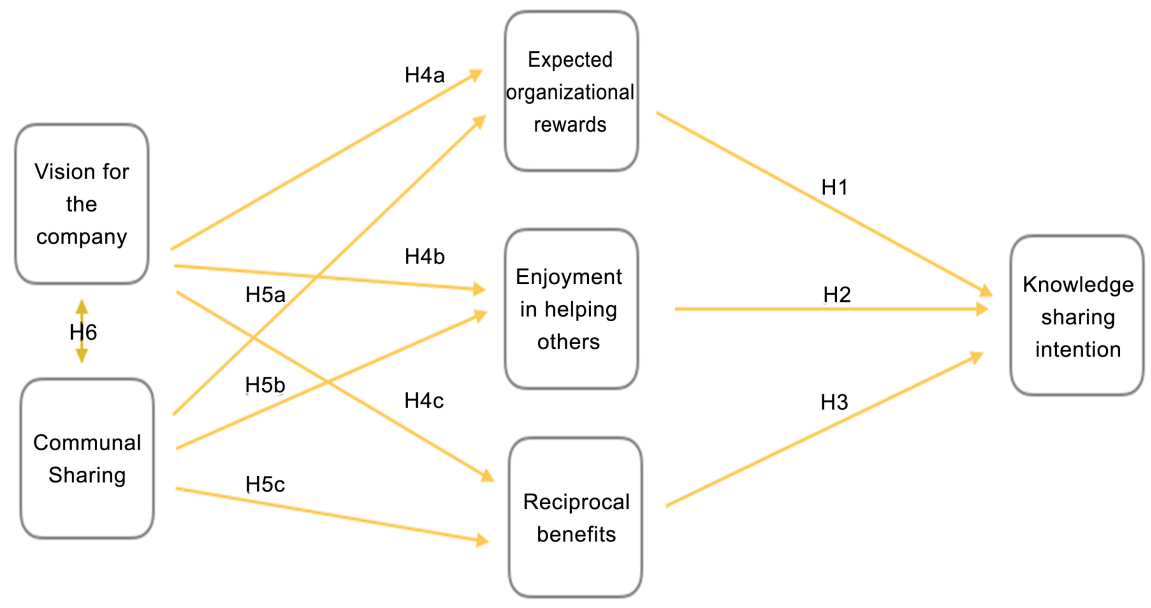

Figure 1. Research framework. 
Others (HE) and Reciprocal Benefits (RB), were adapted from work on large enterprises [48]. Each consists of four items. Communal Sharing (CS) was adapted from Relational Models Questionnaire [55], consisting of five items. Shared Vision for the Company (VIS) was adopted from research on familiar companies [56], consisting of three items. The final item, Knowledge Sharing Intention (KSINT), was adapted from research on knowledge sharing intention [48]. The questionnaire was divided into seven sections with a short background question sheet followed by the questions. A sample section of the question sheet is attached to the Appendix of the article.

The clarity of the measures and the online survey form was tested with four practitioners and four academics, and minor adjustments were made to the wordings of the survey items based on the pilot.

\subsection{Sample and Data Collection}

The created survey was sent to 538 individual core members of young startups. These individuals were chosen as the target population based on their activeness in their local startup ecosystems and by their companies meeting the previously derived definition of a startup. A personalised email inviting the target to fill in the online survey were sent in October 2017 with a reminder email sent three weeks later. Out of the 538 individuals contacted, 111 selected to take part in the survey, leading to a response rate of $20.6 \%$. The characteristics of the respondents are described in Table 1.

Table 1. Sample description $(\mathrm{n}=111)$.

\begin{tabular}{|c|c|c|c|}
\hline Age & \# of respondents & Gender & \# of respondents \\
\hline $20-25$ & 20 & Female & 33 \\
\hline $26-30$ & 15 & Male & 77 \\
\hline $31-35$ & 24 & Prefer not to disclose & 1 \\
\hline $36-40$ & 17 & & \\
\hline over 40 & 35 & & \\
\hline Education level & \# of respondents & & \\
\hline $\begin{array}{c}\text { High School/Vocational } \\
\text { school }\end{array}$ & 3 & $\begin{array}{l}\text { Tenure in the startup } \\
\text { industry (years) }\end{array}$ & \# of respondents \\
\hline Undergraduate & 48 & 1 or less & 3 \\
\hline Graduate & 50 & 1 to 2 & 21 \\
\hline \multirow[t]{2}{*}{ Post-graduate } & 10 & 2 to 3 & 27 \\
\hline & & 3 to 4 & 14 \\
\hline Startup size & \# of respondents & 4 to 5 & 15 \\
\hline Less than 10 & 52 & 5 to 6 & 9 \\
\hline $10-20$ & 10 & over 6 & 22 \\
\hline $21-30$ & 7 & & \\
\hline $30-50$ & 4 & & \\
\hline $51-500$ & 9 & & \\
\hline Over 500 & 29 & & \\
\hline
\end{tabular}


The respondents were $69 \%$ male, on average in their early 30s with approximately three years spent in the startup industry. Most respondents (88\%) had finished either a graduate degree or an undergraduate degree. The respondents lived in regionally varied countries with the three most popular answers being Japan (32\%) Finland (15\%) and USA (7\%). Most of the responders worked in companies with less than ten members. Twenty-nine individuals worked in organizations with over 500 members but based on closer inspection these organizations with a majority of members are freelance members, such as food and beverage delivery companies, with only a small core team who mainly interact amongst themselves.

\section{Analysis and Results}

The survey results were analysed by Confirmatory Factor Analysis, CFA, using Structural Equation Modelling. This methodology was chosen because of its capabilities of analysing the causal links connecting theoretical constructs of interest [57] and it has been widely used in previous knowledge sharing research. The analysis was done with the R Studio (version 3.4.3) software [58] using the lavaan package (version 0.5-23.1097) [59]. Before starting, the filled surveys were screened for outliers using Mahalanobis distances [60] leading to the exclusion of four outliers from further analysis.

Due to the single source of data, the gathered data was checked for common method variance with Harman's one-variable test following the instructions of Podsakoff et al. [61]. In this test, a significant common variance would be indicated by one common factor accounting for the majority of covariance between variables. The analysis resulted in three eigenvectors with values over one with the first factor accounting for $30 \%$ of the total variance. The results indicate that common method variance is not likely to have caused the studied relationships.

\subsection{Measurement Model}

\subsubsection{Convergent Validity}

CFA was used to analyse the validity and reliability of the constructs used in the measurement model. Item loadings of the factors were analysed, and items with loadings of less than 0.6 were dropped as suggested [62]. All composite reliability of the measures ranges from 0.72 to 0.95 , which are higher than the suggested cut off for latent constructs [63]. Factor loadings and composite reliabilities are shown in Table 2.

\subsubsection{Discriminant Validity}

The discriminant validity was also analysed, shown in Table 3, in addition to standard deviations and means. The average variance extracted by each construct are shown on the diagonal with other entries of the table showing the squared correlations. The analysis shows adequate validity of the discriminants as all of the variances extracted are larger than the squared correlations [64]. 
Table 2. Factor loadings and component reliabilities.

\begin{tabular}{|c|c|c|c|}
\hline Construct & Measure & Factor loading & Component reliability \\
\hline \multirow[t]{3}{*}{ Vision For The Company (Vis) } & VIS1 & 0.93 & 0.84 \\
\hline & VIS2 & 0.86 & \\
\hline & VIS3 & 0.88 & \\
\hline \multirow[t]{3}{*}{ Communal Sharing (CS) } & CS3 & 0.74 & 0.84 \\
\hline & CS4 & 0.92 & \\
\hline & CS5 & 0.78 & \\
\hline \multirow[t]{4}{*}{ Expected Organizational Rewards (OR) } & OR1 & 0.88 & 0.72 \\
\hline & OR2 & 0.91 & \\
\hline & OR3 & 0.73 & \\
\hline & OR4 & 0.67 & \\
\hline \multirow[t]{4}{*}{ Enjoyment In Helping Others (HE) } & HE1 & 0.64 & 0.95 \\
\hline & HE2 & 0.81 & \\
\hline & HE3 & 0.90 & \\
\hline & $\mathrm{HE} 4$ & 0.92 & \\
\hline \multirow[t]{3}{*}{ Reciprocal Benefits (RB) } & RB1 & 0.76 & 0.85 \\
\hline & RB2 & 0.74 & \\
\hline & RB4 & 0.85 & \\
\hline \multirow[t]{4}{*}{ Knowledge Sharing Intention(KSINT) } & KSINT1 & 0.77 & 0.85 \\
\hline & KSINT2 & 0.97 & \\
\hline & KSINT3 & 0.91 & \\
\hline & KSINT4 & 0.62 & \\
\hline
\end{tabular}

Table 3. Mean, SD, AVE and squared correlations.

\begin{tabular}{ccccccccc}
\hline & Mean & SD & VIS & CS & OR & HE & RB & KSINT \\
\hline VIS & 5.05 & 1.53 & $\mathbf{0 . 6 6}$ & & & & & \\
CS & 4.18 & 1.40 & 0.24 & $\mathbf{0 . 5 4}$ & & & & \\
OR & 3.73 & 1.92 & 0.19 & 0.06 & $\mathbf{0 . 7 9}$ & & & \\
HE & 6.29 & 0.93 & 0.15 & 0.09 & 0.04 & $\mathbf{0 . 6 6}$ & & \\
RB & 5.59 & 1.37 & 0.34 & 0.20 & 0.15 & 0.30 & $\mathbf{0 . 6 3}$ & \\
KSINT & 7.56 & 1.61 & 0.24 & 0.14 & 0.07 & 0.45 & 0.49 & $\mathbf{0 . 7 2}$ \\
\hline
\end{tabular}

\subsection{Structural Model}

Structural fit, shown in Figure 2, was assessed through a Normed $\chi^{2}\left(=1.78, \chi^{2}=\right.$ $315.82, \mathrm{df}=177)$, which was smaller than the suggested cut off [65]. Additional measures used to assess structural fit, Comparative Fit Index, CFI $=0.92$, and Tucker-Lewis Index, TLI $=0.90$, were also in the acceptable ranges [66]. Finally, Root Mean Square Error of Approximation, RMSEA $=0.086$ (90\% CI: 0.070 - 


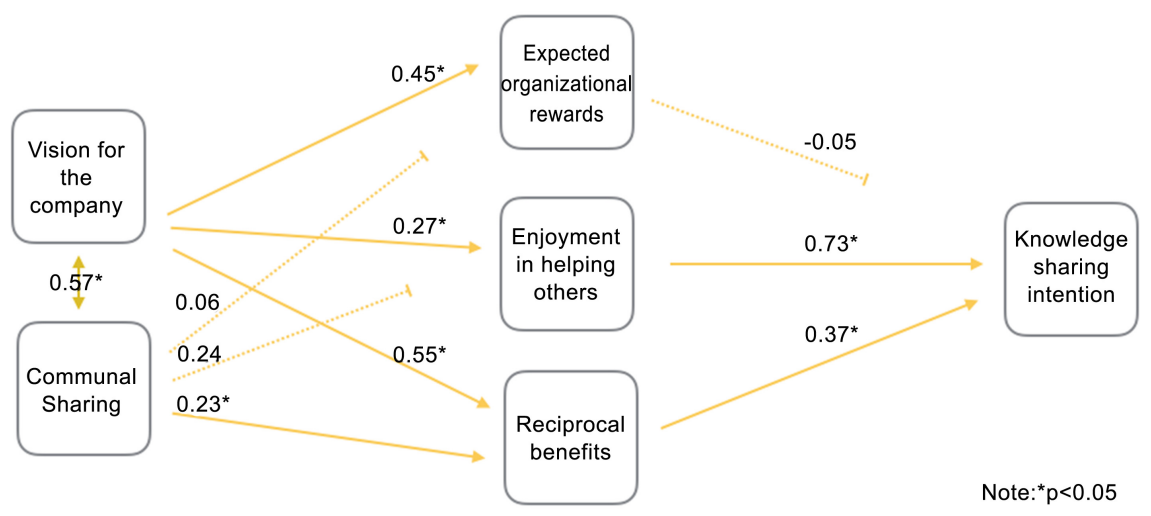

Figure 2. Results of the structural model.

0.101) and Standardized Root Mean Square, $\operatorname{SRMR}=0.10$ were also in the acceptable range [67]. The combination of the measures used indicates an acceptable fit of the measurement model.

Next, the structural model was analysed. Vision for the Company was found to positively influence all three types of knowledge sharing motivations, ( $\mathrm{H} 4 \mathrm{a}$, OR: $\mathrm{t}$-value $=3.6$, path coefficient $=0.45 ; \mathrm{H} 4 \mathrm{~b}, \mathrm{HE}$ : $\mathrm{t}$-value $=2.18$, path coefficient $=0.27 ; \mathrm{H} 4 \mathrm{c}$, RB: $\mathrm{t}$-value $=4.7$, path coefficient $=0.55$ ).

Communal Sharing was found to positively influence Reciprocal Benefits $(\mathrm{H} 5 \mathrm{c}$, $\mathrm{t}$-value $=1.97$, path coefficient $=0.23)$ but not Expected Organizational Rewards $(\mathrm{H} 5 \mathrm{a}, \mathrm{t}$-value $=0.50$, path coefficient $=0.06)$ and Enjoyment in Helping Others $(\mathrm{H} 5 \mathrm{~b}, \mathrm{t}$-value $=1.89$, path coefficient $=0.24)$.

Additionally, there was a significant covariance relationship between Communal Sharing and Vision for the Company $(\mathrm{H} 6, \mathrm{t}-\mathrm{value}=4.30$, path coefficient $=0.57$ ).

For Knowledge Sharing Intention, Reciprocal Benefits $(\mathrm{H} 3, \mathrm{t}$-value $=5.10$, path coefficient $=0.73)$ and Enjoyment in Helping Others $(\mathrm{H} 2$, $\mathrm{t}$-value $=4.0$, path coefficient $=0.37$ ) were found to positively influence Knowledge Sharing Intention. The influence of Expected Organizational Rewards, (H1, OR, t-value $=-0.63$, path coefficient $=-0.05)$ on Knowledge Sharing Intention was not significant.

\section{Discussion}

\subsection{Antecedents of Knowledge Sharing Motivation}

Vision for the company was found to be linked to all three components of knowledge sharing motivation aligning the derived results with previous research indicating vision as a source of motivation [33]. This result is also supported by the answers to a voluntary open question where approximately $1 / 4$ of the answers directly mentioned vision for the company as a motivating factor to work at their startup. Therefore, attention should be paid to communicating the vision of the organization to all of its members. Particularly during such times when there has been a change in the vision as a result of changes in the organi- 
zational goals. Through the use of an adequately communicated vision, the startup can be positioned as a cutting-edge leader in its field [11], which can then help motivate the members of the startup [10] and to recruit more talent [5]. Hence, efforts should be made to continually communicate the vision of the startup to its members and stakeholders.

In regards to CS culture, this type of culture was found to positively influence reciprocal benefits, which aligns with Fiske's [14] theoretical foundations and the work of Boer et al. [54], who theorised CS culture's positive influence motivation to share knowledge. Fiske [14] also predicted that expected organizational rewards would not fit the cultural norms in organizations with a CS culture, which was supported by the analysis as there was a not significant link to expected organizational rewards. Unexpectedly, CS culture was not found to influence enjoyment in helping others. One possible reason for this finding is that knowledge sharing is seen as an obligation, i.e., aligning with reciprocal benefits, and as an activity that is just expected to be carried out based on the organizational norms. This reasoning aligns with Fiske's description of CS culture where contributions and access to common goods, i.e., knowledge, is expected for all members, and align with the logic from Wasko and Faraj [68] who summarised the reasons for sharing knowledge as: "it is what one does." (p.155).

\subsection{Knowledge Sharing Motivation and Intention}

When an individual first shares their knowledge, she receives information back about her performance in regards to others and about her level of competence thus boosting her intrinsic motivation to share. Based on Lindenberg [31], the increased motivation then likely increases her knowledge sharing intention, which was supported by the findings as enjoyment in helping others was positively linked to knowledge sharing intention. Previous studies have found similar results in larger companies [48], but this is the first-time the role of enjoyment in helping others as a motivating factor for knowledge sharing has been confirmed in the startup context. By helping others, the individual also increases the reciprocal benefits that can be derived in the future. The found positive influence of reciprocal benefits on knowledge sharing intention was predicted by both the studied antecedents and Lindenberg's categorization of motivation [31]. Similar results have been found in research targeting established companies [7] [52] but this is the first time it has been confirmed in the startup context. These results emphasise the importance of the two intrinsic motivation types for knowledge sharing.

Expected Organizational Rewards were not linked to knowledge sharing intention, which is contrary to the previous findings in startups [47]. There are two possible reasons for this: first, it is hypothesised that this is due to the organizational culture, as in CS relations no payment is expected for the use and sharing of knowledge [14]. This logic can also be seen when comparing with the findings from large companies. Lin's [48] described that managers did not value 
expected organizational rewards due to their high positions. However, what is proposed here is that the effectiveness of incentives for knowledge sharing is dependent on organizational culture and norms, not the position of the individual. This means that managers would expect to receive and contribute knowledge due to cultural norms instead of expecting having to pay or to be rewarded for these activities. Inside young startups, this line of reasoning aligns with Lindenberg [31], who stated that in tightly-knit groups with strong reciprocal norms, direct gain-frame motives would be forbidden. A second possible reason relates to the fact that this study targeted sharing that takes place outside of a knowledge management system, which makes measuring the utility of one's sharing hard, which would make it challenging to create incentives that are correctly aligned with knowledge sharing.

\section{Conclusions}

This article makes three contributions: first, it is argued that startups should not be treated as small companies. Second, this article contributes to the discussion on the influence of context on knowledge sharing and particularly on the effectiveness of incentives. Third, the organizational culture within the startup organizations is captured by the concept of Communal Sharing, CS, first presented in Fiske [14] and to the best of our knowledge, this is the first time CS has been used in a quantitative study within knowledge management research.

The results emphasise the importance of intrinsic motivation as a source of knowledge sharing motivation in startups and that founders can help increase members' intrinsic motivation through their actions. The derived results contribute to the discussion on knowledge sharing in startups by emphasizing the importance of a well-communicated vision and organizational culture as sources of knowledge-sharing motivation and to the discussion on the influence of context on the effectiveness of incentives.

Practical implications from the derived results emphasise the importance of vision and organizational culture. This leads to two key actions, which should be included in the work of all managers and core team members in startups: First, constant communication of the organizational vision. As the startup grows, vision communication is frequently forgotten but as was shown vision plays an important motivating role for sharing. Second, the significance of building an organizational culture. Fixing a broken culture will be time-consuming and expensive [10]; hence attention needs to be paid from the start.

The presented results have two main limitations: first, there are many aspects in which startups differ from small companies. While modifications were made to the used instruments to capture context better, there is a need for the development of new statistical instruments that capture the characteristics of startups better. Second, while efforts were made to limit common method variance, additional data sources besides surveys should be created for future use.

In future research, researchers should strive to better understand how daily 
knowledge sharing takes place in early-stage startups. New statistical instruments might be able to better capture the intricacies of the startup context, which would lead to a better understanding of how startups and knowledge sharing practices evolve. Second, if knowledge sharing is driven by intrinsic motivation then why have previous results also indicated a positive the influence of extrinsic motivation? Analysis of incentive types could prove fruitful in the pursuit of this question.

\section{Conflicts of Interest}

The authors declare no conflicts of interest regarding the publication of this paper.

\section{References}

[1] Ouimet, P. and Zarutskie, R. (2014) Who Works for Startups? The Relation between Firm Age, Employee Age, and Growth. Journal of Financial Economics, 112, 386-407. https://doi.org/10.1016/j.jbusres.2012.01.011

[2] Blank, S. and Dorf, B. (2012) The Startup Owner's Manual: The Step-by-Step Guide for Building a Great Company. BookBaby, Pennsauken.

[3] Aulet, W. and Murray, F. (2013) A Tale of Two Entrepreneurs: Understanding Differences in the Types of Entrepreneurship in the Economy. https://doi.org/10.2139/ssrn.2259740

[4] Ensley, M.D. and Pearce, C.L. (2001) Shared Cognition in Top Management Teams: Implications for New Venture Performance. Journal of Organizational Behavior: The International Journal of Industrial, Occupational and Organizational Psychology and Behavior, 22, 145-160. https://doi.org/10.1002/job.83

[5] Moser, K.J., Tumasjan, A. and Welpe, I.M. (2017) Small But Attractive: Dimensions of New Venture Employer Attractiveness and the Moderating Role of Applicants' Entrepreneurial Behaviors. Journal of Business Venturing, 32, 588-610. https://doi.org/10.1016/j.jbusvent.2017.05.001

[6] de Mol, E., Khapova, S.N. and Elfring, T. (2015) Entrepreneurial Team Cognition: A Review. International Journal of Management Reviews, 17, 232-255. https://doi.org/10.1111/ijmr.12055

[7] AlShamsi, O. and Ajmal, M. (2018) Critical Factors for Knowledge Sharing in Technology-Intensive Organizations: Evidence from UAE Service Sector. Journal of Knowledge Management, 22, 384-412. https://doi.org/10.1108/JKM-05-2017-0181

[8] Marmer, M., Herrmann, B.L., Dogrultan, E., Berman, R., Eesley, C. and Blank, S. (2011) Startup Genome Report Extra: Premature Scaling. Startup Genome, 10, 1-56.

[9] Oe, A. and Mitsuhashi, H. (2013) Founders' Experiences for Startups' Fast Break-Even. Journal of Business Research, 66, 2193-2201. https://doi.org/10.1016/j.jbusres.2012.01.011

[10] Baron, J.N. and Hannan, M.T. (2002) Organizational Blueprints for Success in High-Tech Start-Ups: Lessons from the Stanford Project on Emerging Companies. California Management Review, 44, 8-36. https://doi.org/10.2307/41166130

[11] Santos, F.M. and Eisenhardt, K.M. (2009) Constructing Markets and Shaping Boundaries: Entrepreneurial Power in Nascent Fields. Academy of Management Journal, 52, 643-671. https://doi.org/10.5465/amj.2009.43669892

[12] Sergeeva, A. and Andreeva, T. (2016) Knowledge Sharing Research: Bringing Con- 
text Back in. Journal of Management Inquiry, 25, 240-261. https://doi.org/10.1177/1056492615618271

[13] Centobelli, P., Cerchione, R. and Esposito, E. (2017) Knowledge Management in Startups: Systematic Literature Review and Future Research Agenda. Sustainability, 9, 361. https://doi.org/10.3390/su9030361

[14] Fiske, A.P. (1992) The Four Elementary Forms of Sociality: Framework for a Unified Theory of Social Relations. Psychological Review, 99, 689. https://doi.org/10.1037/0033-295X.99.4.689

[15] Zaech, S. and Baldegger, U. (2017) Leadership in Start-Ups. International Small Business Journal, 35, 157-177. https://doi.org/10.1177/0266242616676883

[16] Debrulle, J., Maes, J. and Sels, L. (2014) Start-Up Absorptive Capacity: Does the Owner's Human and Social Capital Matter? International Small Business Journal, 32, 777-801. https://doi.org/10.1177/0266242612475103

[17] Eisenmann, T.R., Ries, E. and Dillard, S. (2012) Hypothesis-Driven Entrepreneurship: The Lean Startup. Harvard Business School Entrepreneurial Management Case, 812-095.

[18] De Clercq, D., Dimov, D. and Thongpapanl, N. (2013) Organizational Social Capital, Formalization, and Internal Knowledge Sharing in Entrepreneurial Orientation Formation. Entrepreneurship Theory and Practice, 37, 505-537. https://doi.org/10.1111/etap.12021

[19] Wang, S. and Noe, R.A. (2010) Knowledge Sharing: A Review and Directions for Future Research. Human Resource Management Review, 20, 115-131. https://doi.org/10.1016/j.hrmr.2009.10.001

[20] Cabrera, A. and Cabrera, E.F. (2002) Knowledge-Sharing Dilemmas. Organization Studies, 23, 687-710. https://doi.org/10.1177/0170840602235001

[21] Gibbert, M. and Krause, H. (2002) Practice Exchange in a Best Practice Marketplace. In: Davenport, T.H. and Probst, G.J.B., Eds., Knowledge Management Case Book: Siemens Best Practices, Publicis Corporate Publishing, Erlangen, 89-105.

[22] Witherspoon, C.L., Bergner, J., Cockrell, C. and Stone, D.N. (2013) Antecedents of Organizational Knowledge Sharing: A Meta-Analysis and Critique. Journal of Knowledge Management, 17, 250-277. https://doi.org/10.1108/13673271311315204

[23] Lam, A. and Lambermont-Ford, J.P. (2010) Knowledge Sharing in Organisational Contexts: A Motivation-Based Perspective. Journal of Knowledge Management, 14, 51-66. https://doi.org/10.1108/13673271011015561

[24] Nonaka, I. and Konno, N. (1998) The Concept of "Ba": Building a Foundation for Knowledge Creation. California Management Review, 40, 40-54. https://doi.org/10.2307/41165942

[25] Allen, T.J., Gloor, P., Fronzetti Colladon, A., Woerner, S.L. and Raz, O. (2016) The Power of Reciprocal Knowledge Sharing Relationships for Startup Success. Journal of Small Business and Enterprise Development, 23, 636-651. https://doi.org/10.1108/JSBED-08-2015-0110

[26] Ryan, R.M. and Deci, E.L. (2000) Intrinsic and Extrinsic Motivations: Classic Definitions and New Directions. Contemporary Educational Psychology, 25, 54-67. https://doi.org/10.1006/ceps.1999.1020

[27] Cameron, J., Banko, K.M. and Pierce, W.D. (2001) Pervasive Negative Effects of Rewards on Intrinsic Motivation: The Myth Continues. The Behavior Analyst, 24, 1-44. https://doi.org/10.1007/BF03392017

[28] Deci, E.L., Koestner, R. and Ryan, R.M. (1999) A Meta-Analytic Review of Experi- 
ments Examining the Effects of Extrinsic Rewards on Intrinsic Motivation. Psychological Bulletin, 125, 627. https://doi.org/10.1037//0033-2909.125.6.627

[29] Cerasoli, C.P., Nicklin, J.M. and Ford, M.T. (2014) Intrinsic Motivation and Extrinsic Incentives Jointly Predict Performance: A 40-Year Meta-Analysis. Psychological Bulletin, 140, 980. https://doi.org/10.1037/a0035661

[30] Holmstrom, B. and Milgrom, P. (1991) Multitask Principal-Agent Analyses: Incentive Contracts, Asset Ownership, and Job Design. The Journal of Law, Economics, \& Organization, 7, 24. https://doi.org/10.1093/jleo/7.special_issue.24

[31] Lindenberg, S. (2001) Intrinsic Motivation in a New Light. Kyklos, 54, 317-342. https://doi.org/10.1111/1467-6435.00156

[32] Ruvio, A., Rosenblatt, Z. and Hertz-Lazarowitz, R. (2010) Entrepreneurial Leadership Vision in Nonprofit vs. For-Profit Organizations. The Leadership Quarterly, 21, 144-158. https://doi.org/10.1016/j.leaqua.2009.10.011

[33] Shinkle, G.A. (2012) Organizational Aspirations, Reference Points, and Goals: Building on the Past and Aiming for the Future. Journal of Management, 38, 415-455. https://doi.org/10.1177/0149206311419856

[34] Kirkpatrick, S.A. (2017) Understanding the Role of Vision, Mission, and Values in the HPT Model. Performance Improvement, 56, 6-14. https://doi.org/10.1002/pfi.21689

[35] Baum, J.R., Locke, E.A. and Kirkpatrick, S.A. (1998) A Longitudinal Study of the Relation of Vision and Vision Communication to Venture Growth in Entrepreneurial Firms. Journal of Applied Psychology, 83, 43.

https://doi.org/10.1037/0021-9010.83.1.43

[36] Schein, E.H. (1985) Organisational Culture and Leadership: A Dynamic View. San Francisco.

[37] O’Reilly III, C.A., Caldwell, D.F., Chatman, J.A. and Doerr, B. (2014) The Promise and Problems of Organizational Culture: CEO Personality, Culture, and Firm Performance. Group \& Organization Management, 39, 595-625. https://doi.org/10.1177/1059601114550713

[38] Mathias, B.D. and Williams, D.W. (2018) Giving up the Hats? Entrepreneurs' Role Transitions and Venture Growth. Journal of Business Venturing, 33, 261-277. https://doi.org/10.1016/j.jbusvent.2017.12.007

[39] Amabile, T.M. (1997) Motivating Creativity in Organizations: On Doing What You Love and Loving What You Do. California Management Review, 40, 39-58. https://doi.org/10.2307/41165921

[40] Nelson, A.J. (2014) From the Ivory Tower to the Startup Garage: Organizational Context and Commercialization Processes. Research Policy, 43, 1144-1156. https://doi.org/10.1016/j.respol.2014.04.011

[41] Giardino, C., Unterkalmsteiner, M., Paternoster, N., Gorschek, T. and Abrahamsson, P. (2014) What Do We Know about Software Development in Startups? IEEE Software, 31, 28-32. https://doi.org/10.1109/MS.2014.129

[42] Jing, F.F., Avery, G.C. and Bergsteiner, H. (2014) Enhancing Performance in Small Professional Firms through Vision Communication and Sharing. Asia Pacific Journal of Management, 31, 599-620. https://doi.org/10.1007/s10490-013-9345-9

[43] O'Connor, E. (2002) Storied Business: Typology, Intertextuality, and Traffic in Entrepreneurial Narrative. The Journal of Business Communication, 39, 36-54. https://doi.org/10.1177/002194360203900103

[44] Perkins, G., Lean, J. and Newbery, R. (2017) The Role of Organizational Vision in 
Guiding Idea Generation within SME Contexts. Creativity and Innovation Management, 26, 75-90. https://doi.org/10.1111/caim.12206

[45] Lin, H.F. (2007) Knowledge Sharing and Firm Innovation Capability: An Empirical Study. International Journal of Manpower, 28, 315-332. https://doi.org/10.1108/01437720710755272

[46] Edelman, L.F., Brush, C.G., Manolova, T.S. and Greene, P.G. (2010) Start-up Motivations and Growth Intentions of Minority Nascent Entrepreneurs. Journal of Small Business Management, 48, 174-196. https://doi.org/10.1111/j.1540-627X.2010.00291.x

[47] Kagan, E., Lovejoy, W.S. and Leider, S. (2017) Designing Incentives in Startup Teams: Form and Timing of Equity Contracting. Ross School of Business Paper No. 1372. https://doi.org/10.2139/ssrn.3037444

[48] Lin, H.F. (2007) Effects of Extrinsic and Intrinsic Motivation on Employee Knowledge Sharing Intentions. Journal of Information Science, 33, 135-149. https://doi.org/10.1177/0165551506068174

[49] Fehr, E. and Gintis, H. (2007) Human Motivation and Social Cooperation: Experimental and Analytical Foundations. Annual Review of Sociology, 33, 43-64. https://doi.org/10.1146/annurev.soc.33.040406.131812

[50] Kube, S., Maréchal, M.A. and Puppe, C. (2012) The Currency of Reciprocity: Gift Exchange in the Workplace. American Economic Review, 102, 1644-1662. https://doi.org/10.1257/aer.102.4.1644

[51] Fehr, E., Fischbacher, U. and Gächter, S. (2002) Strong Reciprocity, Human Cooperation, and the Enforcement of Social Norms. Human Nature, 13, 1-25. https://doi.org/10.1007/s12110-002-1012-7

[52] Hau, Y.S., Kim, B., Lee, H. and Kim, Y.G. (2013) The Effects of Individual Motivations and Social Capital on Employees' Tacit and Explicit Knowledge Sharing Intentions. International Journal of Information Management, 33, 356-366. https://doi.org/10.1016/j.ijinfomgt.2012.10.009

[53] Serenko, A. and Bontis, N. (2016) Negotiate, Reciprocate, or Cooperate? The Impact of Exchange Modes on Inter-Employee Knowledge Sharing. Journal of Knowledge Management, 20, 687-712. https://doi.org/10.1108/JKM-10-2015-0394

[54] Boer, N.I., Berends, H. and Van Baalen, P. (2011) Relational Models for Knowledge Sharing Behavior. European Management Journal, 29, 85-97. https://doi.org/10.1016/j.emj.2010.10.009

[55] Haslam, N. and Fiske, A.P. (1999) Relational Models Theory: A Confirmatory Factor Analysis. Personal Relationships, 6, 241-250. https://doi.org/10.1111/j.1475-6811.1999.tb00190.x

[56] Mustakallio, M., Autio, E. and Zahra, S.A. (2002) Relational and Contractual Governance in Family Firms: Effects on Strategic Decision Making. Family Business Review, 15, 205-222. https://doi.org/10.1111/j.1741-6248.2002.00205.x

[57] Shah, R. and Goldstein, S.M. (2006) Use of Structural Equation Modeling in Operations Management Research: Looking Back and Forward. Journal of Operations Management, 24, 148-169. https://doi.org/10.1016/j.jom.2005.05.001

[58] Team, R. (2015) RStudio: Integrated Development for R. RStudio, Inc., Boston. http://www.rstudio.com

[59] Rosseel, Y. (2012) Lavaan: An R Package for Structural Equation Modeling and More. Version 0.5-12 (BETA). Journal of Statistical Software, 48, 1-36. https://doi.org/10.18637/jss.v048.i02 
[60] Cousineau, D. and Chartier, S. (2010) Outliers Detection and Treatment: A Review. International Journal of Psychological Research, 3, 58-67. https://doi.org/10.21500/20112084.844

[61] Podsakoff, P.M., MacKenzie, S.B. and Podsakoff, N.P. (2012) Sources of Method Bias in Social Science Research and Recommendations on How to Control It. Annual Review of Psychology, 63, 539-569. https://doi.org/10.1146/annurev-psych-120710-100452

[62] Hair, J.F. anderson, R.E., Tatham, R.L. and Balck, W.C. (1998) Multivariate Data Analysis. Prentice Hall International, Upper Saddle River.

[63] Nunnally, J.C. and Bernstein, I.H. (1994) Psychometric Theory. McGraw-Hill Series in Psychology Vol. 3, McGraw-Hill, New York.

[64] Fornell, C. and Larcker, D.F. (1981) Structural Equation Models with Unobservable Variables and Measurement Error: Algebra and Statistics. Journal of Marketing Research, 18, 382-388. https://doi.org/10.1177/002224378101800313

[65] Bagozzi, R.P. and Yi, Y. (1988) On the Evaluation of Structural Equation Models. Journal of the Academy of Marketing Science, 16, 74-94. https://doi.org/10.1007/BF02723327

[66] Gefen, D., Straub, D. and Boudreau, M.C. (2000) Structural Equation Modeling and Regression: Guidelines for Research Practice. Communications of the Association for Information Systems, 4, 7. https://doi.org/10.17705/1CAIS.00407

[67] Browne, M.W. and Cudeck, R. (1993) Alternative Ways of Assessing Model Fit. Sociological Methods \& Research, 21, 230-258.

[68] Wasko, M.M. and Faraj, S. (2000) "It Is What One Does": Why People Participate and Help Others in Electronic Communities of Practice. The Journal of Strategic Information Systems, 9, 155-173. https://doi.org/10.1016/S0963-8687(00)00045-7 


\section{Appendix-Sample Survey}

About the stage of the startup

Introductory text: This section is to understand a bit more about the startup stage

When was the company established (approximately, year.month e.g. 2015.12):

Funding stage of the company:

- Self-funded/bootstrapping

- Family and friends

- Angel/seed funding

- Series A

- Series B or later

- I don't know

Other:

Section 1-About your work in the organization

Introductory text. This section is used to understand your motivation for your job a bit better.

I receive a fixed salary (base salary, complements, etc.) for my activity in the organization

Totally disagree

Totally agree

$\begin{array}{lllllll}1 & 2 & 3 & 4 & 5 & 6 & 7\end{array}$

The organization explicitly recognizes my job (through rewards, mentions in the organization's magazine, intranet, advertisement board, etc.)

Totally disagree Totally agree

$\begin{array}{lllllll}1 & 2 & 3 & 4 & 5 & 6 & 7\end{array}$

The organization offers me the possibility for promotion.

Totally disagree

Totally agree

$$
\begin{array}{lllllll}
1 & 2 & 3 & 4 & 5 & 6 & 7
\end{array}
$$

The organization offers stability and continuity in my job.

Totally disagree Totally agree

$\begin{array}{lllllll}1 & 2 & 3 & 4 & 5 & 6 & 7\end{array}$

My activity in the organization lets me improve as a person, enhance my self-confidence, get mature, self-accomplish...

Totally disagree

Totally agree

$\begin{array}{lllllll}1 & 2 & 3 & 4 & 5 & 6 & 7\end{array}$

I have autonomy in my job and I can contribute with my ideas.

Totally disagree Totally agree

$$
\begin{array}{lllllll}
1 & 2 & 3 & 4 & 5 & 6 & 7
\end{array}
$$

I consider this organization honest and coherent with its mission.

Totally disagree Totally agree

$\begin{array}{lllllll}1 & 2 & 3 & 4 & 5 & 6 & 7\end{array}$

I have an organization's sense of belonging (I feel myself as an organization member, loyal and involved to it).

Totally disagree

Totally agree 
$\begin{array}{lllllll}1 & 2 & 3 & 4 & 5 & 6 & 7\end{array}$

What motivates you to work at your current organization?

Section 2-About knowledge sharing

Introductory text: In this section "knowledge sharing" means the act of sharing and making knowledge available throughout the organization with the goal of increasing knowledge utilization. This can happen for example via email, instant messaging or in meetings. This is the longest section (16 multiple choice questions) and the other sections after this will be shorter (16 questions in total).

I will receive a higher salary in return for my knowledge sharing.

Totally disagree Totally agree

$\begin{array}{lllllll}1 & 2 & 3 & 4 & 5 & 6 & 7\end{array}$

I will receive a higher bonus in return for my knowledge sharing.

Totally disagree Totally agree

$\begin{array}{lllllll}1 & 2 & 3 & 4 & 5 & 6 & 7\end{array}$

I will receive increased promotion opportunities in return for my knowledge sharing.

Totally disagree Totally agree

$\begin{array}{lllllll}1 & 2 & 3 & 4 & 5 & 6 & 7\end{array}$

I will receive increased job security in return for my knowledge sharing.

Totally disagree Totally agree

$\begin{array}{lllllll}1 & 2 & 3 & 4 & 5 & 6 & 7\end{array}$

I strengthen ties between existing members of the organization and myself.

Totally disagree Totally agree

$$
\begin{array}{lllllll}
1 & 2 & 3 & 4 & 5 & 6 & 7
\end{array}
$$

I expand the scope of my association with other organization members.

Totally disagree

Totally agree

$\begin{array}{lllllll}1 & 2 & 3 & 4 & 5 & 6 & 7\end{array}$

I expect to receive knowledge in return when necessary.

Totally disagree

Totally agree

$\begin{array}{lllllll}1 & 2 & 3 & 4 & 5 & 6 & 7\end{array}$

I believe that my future requests for knowledge will be answered.

Totally disagree Totally agree

$\begin{array}{lllllll}1 & 2 & 3 & 4 & 5 & 6 & 7\end{array}$

I am confident in my ability to provide knowledge that others in my organization consider valuable.

Totally disagree Totally agree

$$
\begin{array}{lllllll}
1 & 2 & 3 & 4 & 5 & 6 & 7
\end{array}
$$

I have the expertise required to provide valuable knowledge for my organization.

Totally disagree Totally agree

$\begin{array}{lllllll}1 & 2 & 3 & 4 & 5 & 6 & 7\end{array}$


It does not really make any difference whether I share my knowledge with colleagues.

Totally disagree Totally agree

$\begin{array}{lllllll}1 & 2 & 3 & 4 & 5 & 6 & 7\end{array}$

Most other employees can provide more valuable knowledge than I can.

Totally disagree Totally agree

$\begin{array}{lllllll}1 & 2 & 3 & 4 & 5 & 6 & 7\end{array}$

I enjoy sharing my knowledge with colleagues.

Totally disagree Totally agree

$\begin{array}{lllllll}1 & 2 & 3 & 4 & 5 & 6 & 7\end{array}$

I enjoy helping colleagues by sharing my knowledge.

Totally disagree Totally agree

$\begin{array}{lllllll}1 & 2 & 3 & 4 & 5 & 6 & 7\end{array}$

It feels good to help someone by sharing my knowledge

Totally disagree Totally agree $\begin{array}{lllllll}1 & 2 & 3 & 4 & 5 & 6 & 7\end{array}$

Sharing my knowledge with colleagues is pleasurable Totally disagree Totally agree

$$
\begin{array}{lllllll}
1 & 2 & 3 & 4 & 5 & 6 & 7
\end{array}
$$

Section 3-Relationships with other people within the organization Introductory text: Half way! 16 multiple choice questions left. In this section, think about a person within the organization that you interact with.

If either of you needs something, the other gives it without expecting anything in return

Not true at all Very true for this

of this relationship relationship

$$
\begin{array}{llllll}
1 & 2 & 3 & 4 & 5 & 6
\end{array}
$$

You feel a moral obligation to feel kind and compassionate to each other Not true at all Very true for this

of this relationship relationship

$\begin{array}{llllll}1 & 2 & 3 & 4 & 5 & 6\end{array}$

The two of you are a unit: you belong together

Not true at all Very true for this of this relationship relationship

$\begin{array}{lllllll}1 & 2 & 3 & 4 & 5 & 6\end{array}$

The two of you tend to develop very similar attitudes and values

Not true at all Very true for this of this relationship relationship

$$
\begin{array}{llllll}
1 & 2 & 3 & 4 & 5 & 6
\end{array}
$$

You feel that you have something unique in common that makes you two essentially the same

Not true at all Very true for this

of this relationship relationship

$\begin{array}{llllll}1 & 2 & 3 & 4 & 5 & 6\end{array}$




\section{Section 4-Shared vision for the organization}

Introductory text. Over half way! 11 questions left. This section deals with how does your vision for the company align with other members.

Organization members share the same vision about their organization

Totally disagree

Totally agree

$$
\begin{array}{lllllll}
1 & 2 & 3 & 4 & 5 & 6 & 7
\end{array}
$$

Organization members are committed to jointly agreed-on goals of the organization

Totally disagree Totally agree

$\begin{array}{lllllll}1 & 2 & 3 & 4 & 5 & 6 & 7\end{array}$

Organization members agree about the long-term development objectives of the organization

Totally disagree Totally agree

$$
\begin{array}{lllllll}
1 & 2 & 3 & 4 & 5 & 6 & 7
\end{array}
$$

\section{Section 5-Perceived need for incentives}

Introductory text: Almost there! 8 questions left! This section is about how do you perceive others and yourself to be motivated by incentives.

How motivated do you think other employees are to do his/her job for external reasons (pay/medical benefits)?

Not at all Completely

$$
\begin{array}{lllllllll}
1 & 2 & 3 & 4 & 5 & 6 & 7 & 8 & 9
\end{array}
$$

How motivated do you think you are to do your job for external reasons (pay/medical benefits)?

Not at all Completely

$$
\begin{array}{lllllllll}
1 & 2 & 3 & 4 & 5 & 6 & 7 & 8 & 9
\end{array}
$$

How motivated do you think other employees are to do his/her job for internal reasons (finding job enjoyable and interesting)

Not at all Completely

$$
\begin{array}{lllllllll}
1 & 2 & 3 & 4 & 5 & 6 & 7 & 8 & 9
\end{array}
$$

What types of incentives (e.g. stock options, cash, more holidays etc.) would motivate you the most at your current job?

Section 6-Knowledge sharing intention

Introductory text: Final Section! Last 4 questions left.

I intend to share knowledge with my colleagues more frequently in the future

Totally disagree Totally agree

$$
\begin{array}{lllllllll}
1 & 2 & 3 & 4 & 5 & 6 & 7 & 8 & 9
\end{array}
$$

I will try to share knowledge with my colleagues

Totally disagree Totally agree

$$
\begin{array}{lllllllll}
1 & 2 & 3 & 4 & 5 & 6 & 7 & 8 & 9
\end{array}
$$

I will always make an effort to share knowledge with my colleagues 
Totally disagree Totally agree

$$
\begin{array}{lllllllll}
1 & 2 & 3 & 4 & 5 & 6 & 7 & 8 & 9
\end{array}
$$

I intend to share knowledge with colleagues who ask

Totally disagree Totally agree

$\begin{array}{lllllllll}1 & 2 & 3 & 4 & 5 & 6 & 7 & 8 & 9\end{array}$

That's it! Thank you very much for your answers! 